\title{
Reduction of Aerodynamically Undesirable Influences Due to Engine Cooling Flow in Road Vehicle
}

\author{
Takuto Sawaguchi, Yoko Takakura* \\ Course of Mechanical Engineering, Graduate School of Engineering, Tokai University, Kanagawa, Japan \\ Email: *takakura@tokai-u.jp
}

How to cite this paper: Sawaguchi, T. and Takakura, Y. (2020) Reduction of Aerodynamically Undesirable Influences Due to Engine Cooling Flow in Road Vehicle. Journal of Flow Control, Measurement \& Visualization, 8, 1-24.

https://doi.org/10.4236/jfcmv.2020.81001

Received: May 26, 2019

Accepted: November 16, 2019

Published: December 18, 2019

Copyright $\odot 2020$ by author(s) and Scientific Research Publishing Inc. This work is licensed under the Creative Commons Attribution International License (CC BY 4.0).

http://creativecommons.org/licenses/by/4.0/

\begin{abstract}
The purpose of this research is to clarify causes for the change in aerodynamic characteristics of a road vehicle model due to engine cooling flow in wind-tunnel experiments with the moving-belt ground board, in order to propose methods to reduce the drag and lift. With regard to engine cooling flow, the air-intake system was adjusted with variable opening area and position for the engine loading system of FF and FR with and without a radiator. A simplified $1 / 5$ scale vehicle model was manufactured with transparent externals around the engine for flow visualization. The overall results show that with enlargement of the opening area, the drag and the front lift increased and the rear lift decreased. The flow visualization and the measurements of underfloor velocity and surface pressure indicated the cause of the characteristics changes. Enlargement of the opening area causes flow disturbance by merging of the scavenging flow and the underfloor flow, which has blockage effects for the upstream of each flow with keeping high pressure in the engine compartment and causes pressure loss under the floor behind the engine unit. The difference between the two engine loading systems lies indirection and location of the engine unit, which causes the differences of how the flow features affect the aerodynamic characteristics. The effect of the radiator is to reduce the range of changes in drag and lift. Finally, it is discussed that the principle of reducing drag and lift is to suppress interference of scavenging flow, and concrete methods are proposed.
\end{abstract}

\section{Keywords}

Engine Loading System, Air-Intake System, Under Floor Velocity, Multipoint Pressure

\section{Introduction}

Recently improvements of fuel efficiency of vehicles become one of most impor- 
tant topics due to aggravation of the global warming and the energy problem, and therefore reduction of the aerodynamic drag that greatly influences the fuel efficiency is proceeded [1]. Aerodynamic drag basically consists of two types, i.e., pressure and friction drags. As for road vehicles, more practical classification is made such as a shape drag (mainly pressure drag), an internal-flow drag, an induced drag, an interference drag and a friction drag. Since the shape drag occupies $75 \%$ of aerodynamic drag of whole car, optimization for configuration has been regarded as most important in aerodynamic developments of cars [1] [2] [3]. History of improvements of the car shape dates back to the 1920s'. The average for the coefficient of drag at that time is about 0.8 , but nowadays that for passenger cars is about 0.3 , which shows the evolution of car shapes during about 100 years. Recently, in order to realize further reduction of aerodynamic drag, attention has focused on reduction of not only the shape drag but also the internal-flow drag. It is generated mainly when the wind blows through the front air intake to the engine compartment for cooling a radiator, an air-conditioning condenser and an engine itself. The internal-flow drag through an engine compartment occupies about $10 \%$ of the whole aerodynamic drag, and today when the shape of the car body has improved, the reduction of the cooling-flow drag begins to be put into emphasis.

To consider the cooling drag, Wiedemann assumed the engine compartment as a huge duct system theoretically [4], Barnard, et al., found experimentally that the outlet angle and location of the duct are critical [5], and Braeder, et al., used a generic car model with a simplified internal duct and showed numerically and experimentally that the cooling air interferes with the external flows, designing a model radiator for pressure loss of the radiator, engine block, etc. [6]. On the other hand, Nouzawa, et al., considered the engine cooling air in the system of a real vehicle consisting of: 1) flow around the front-end shape; 2) flow between the grille and the radiator; and 3) flow within the engine compartment and scavenging, with experimental analysis [7]. Recently numerical simulation on the cooling drag has been carried out in the system as each real vehicle [8] [9] [10]. In addition, with regard to the engine-compartment aerodynamics, other than documentations about drag and cooling efficiency, there are few publications about the running stability such as reduction of lift and about the side-wind stability, and therefore further research will be necessary.

The authors investigated effects of the aerodynamic drag and lift by the engine cooling flow in a simplified vehicle model experimentally with variation of the area and position of an air intake, the engine layouts for FF (Front engine \& Front drive) and FR (Front engine \& Rear drive), and existence and non-existence of a radiator, and concluded that the drag and lift are influenced overall by the intake area [11].

In this paper, for the engine loading systems of FF and FR, both of which are typical drive systems in mass-produced vehicles in Japan, causes for the above change in aerodynamic characteristics are investigated by smoke visualization and measurements of the flow velocity and its RMS (Root Mean Square) under 
the floor and the surface pressure on the vehicle body and engine-transmission unit. Further, between the two engine loading systems, differences of how the flow features affect the aerodynamic characteristics is clarified. Finally, the principle of reducing undesirable influences in aerodynamic drag and lift will be proposed.

\section{Experimental Setup}

\subsection{Test Model}

The design intent of the test model in this study was to simulate the engine cooling flow that can be applied to almost all vehicle types with a front engine by simplifying common items.

A simplified 1/5 scale vehicle model with specifications of Table 1 was produced [11] based on the average dimensions of typical domestic vehicles in Japan. The whole view and detailed dimensions are shown in Figure 1(a) and Figure 1(b), respectively. It was produced with a surface-treated main frame and pasted surface-treated exteriors except for the engine compartment without the undercover: the bonnet and fender were made by transparent acrylic plates for flow visualization. Both the engine part and the transmission part are simplified as a cuboid to form a combined unit, which is shown in Figure 2 with detailed dimensions. The engine compartment can be loaded with the engine-transmission unit in two layouts typical in domestic passenger cars in Japan, as shown in Figure 3(a) and Figure 3(b): one is an engine mounting method called "width placement" for FF cars, and the other is that called "length placement" for FR cars. In the former the unit is located almost at centre of the engine compartment, while in the latter the transmission part is attached to the back board of engine compartment. The engine unit is clamped to the lower main frame.

The front plate is replaceable so that the air-intake opening can have six sorts of inlet heights from $0 \mathrm{~mm}$ to $100 \mathrm{~mm}$ shown in Table 2 and two ways of opening locations, lower position and upper position that become larger from the lower and upper sides, respectively (Figure 4(a) and Figure 4(b)), which are possible by reversing the front plates.

Further, by measuring the loss of pressure coefficient $\left(C_{p}\right)$ in a real vehicle radiator, a radiator model with equivalent $C_{p}$ loss was fabricated by stacking eight steel nets (Figure 4(c)), and installed immediately after the front main frame as

Table 1. Specifications of $1 / 5$ scale car model.

\begin{tabular}{lc}
\hline & Dimension $(\mathrm{mm})$ \\
\hline Full length & 980 \\
Full width & 350 \\
Full height & 315 \\
Wheel base & 670 \\
\hline
\end{tabular}


Table 2. Dimensions of air-intake opening.

\begin{tabular}{lcc}
\hline & Width $(\mathrm{mm})$ & Height $(\mathrm{mm})$ \\
\hline 1 & 180 & 0 \\
2 & 180 & 20 \\
3 & 180 & 40 \\
4 & 180 & 60 \\
5 & 180 & 80 \\
6 & 180 & 100 \\
\hline
\end{tabular}

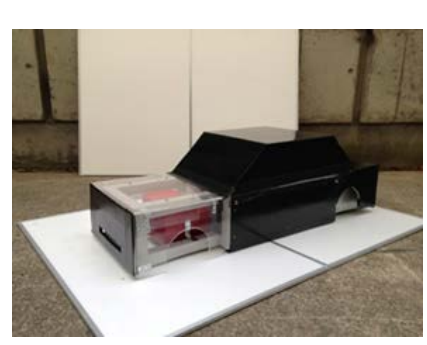

(a) Whole view.

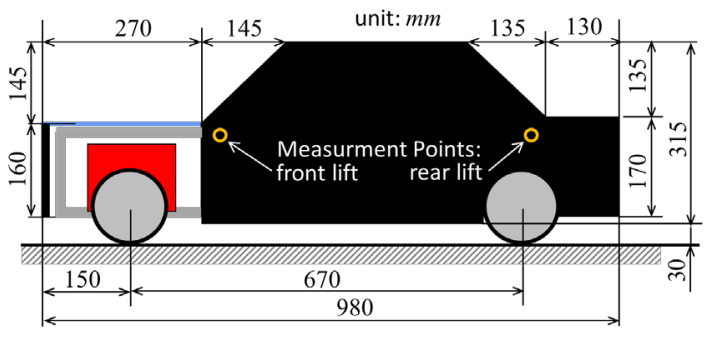

(b) Side view with detailed dimensions.

Figure 1. Simplified 1/5 scale vehicle model.

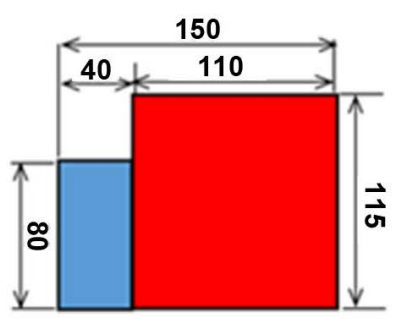

(a) Front view

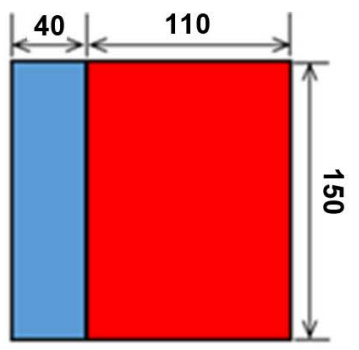

(b) Top view

Figure 2. Combined unit of engine and transmission.

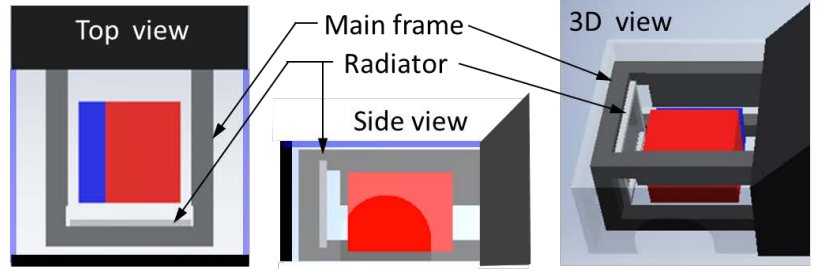

(a) Width placement
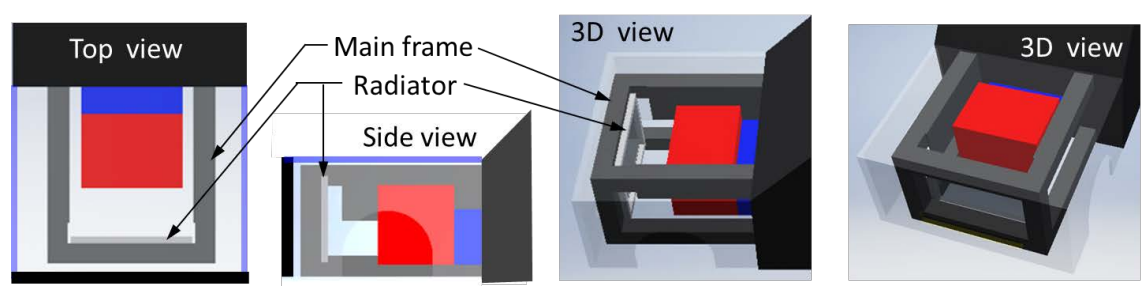

(b) Length placement

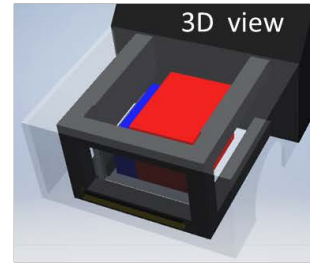

unit : $\mathbf{m m}$

: engine

: transmission

Figure 3. Two types of engine loading system with radiator. 


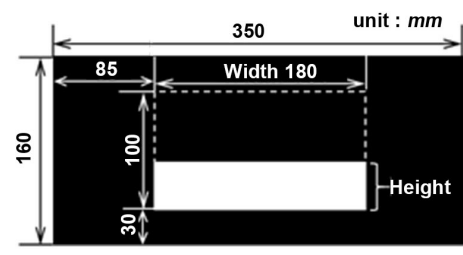

(a) Lower position of opening.

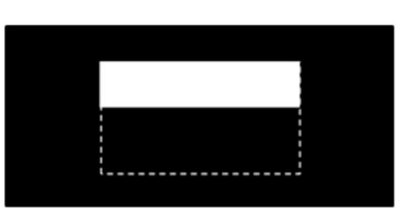

(b) Upper position of opening.

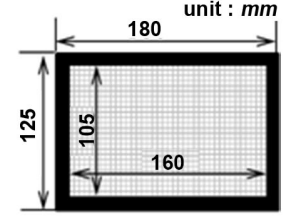

(c) Radiator

Figure 4. Dimension of air-intake opening in front plate and radiator.

shown in Figure 3. Cases without and with a radiator (two ways) were considered.

In the width-placement engine (Figure 3(a)), the airflow coming from the intake opening escapes to the underfloor of the vehicle body through the front, rear and sides of the engine unit, or out of the fender through the wheel housing. In the length-placement engine (Figure 3(b)), there is no spillage through the rear of the engine.

\subsection{Experimental Equipment and Measurement Methods}

Experiments were carried out by using the large-scale low-speed wind tunnel of Tokai University (Nozzle exit: $1.0 \mathrm{~m}$ [height] $\times 1.5 \mathrm{~m}$ [width]; Length of testsection: $2 \mathrm{~m}$ ) [12] and setting the moving belt ground board with a boundary layer suction device between the nozzle outlet and the collector of the wind tunnel.

As indicated in Figure 5(a) and Figure 5(b), on the moving belt the test model was supported by rods and wires connected to strain-gauge type load cells TU-BR200N (TEAC Corporation) for measuring the drag and lift forces. From the load cells the electric signals in voltage were sent through the strain amplifier DPM-601A (Kyowa Electronic Instruments Co., Ltd.) and A/D converter to a computer, with sampling period of $10 \mathrm{~ms}$ and sampling number of 1024 for one measurement. The voltage values were transformed to the force values, and the coefficients of drag and lift consisting of front lift and rear lift, $C_{D}$ and $C_{L}$ consisting of $C_{L F}$ and $C_{L R}$, were computed. In order to reproduce scavenging of the engine cooling air, rotatable wheels were mounted separately from the vehicle body, but the drag on the wheels is not included, because of difficulty to assemble the measurement mechanism so as not to damage the airflow in the engine compartment.

Flows were visualized by smoke producing device with JARI (Japan Automobile Research Institute) system F-235 (Tsukuba Rika Seiki Co. Ltd.).

Underflow velocity with horizontal direction was measured by hot-wire anemometer IHW-100 (Kanomax Japan Inc.), with sampling period of $1 \mathrm{~ms}$ and sampling number of 1024. From the flow velocity, its RMS is computed as turbulent intensity.

Surface pressure about the vehicle model was measured by the simultaneous measurement device for multipoint pressure, for each sensor in which 


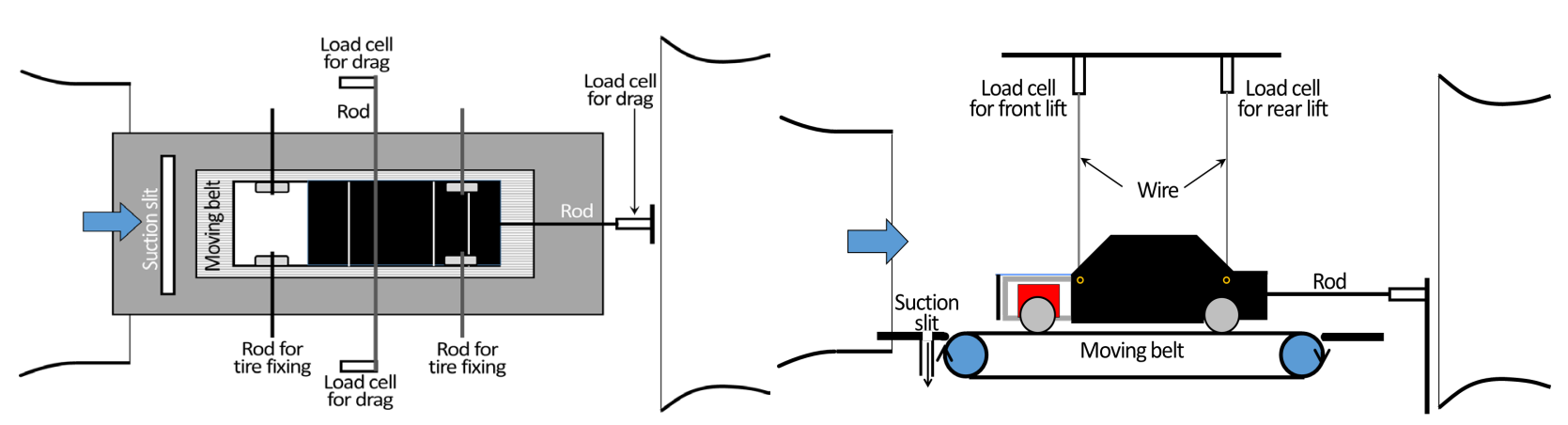

(a) Top view

(b) Side view

Figure 5. Force measurements by load cells for body on moving belt set in wind tunnel.

semiconductor pressure transducer MS4515 (Measurement Specialities Inc.) was adopted, with sampling period of $2 \mathrm{~ms}$ and sampling number of 1024 . This device was produced to measure the surface pressure on car models, and the validation was shown in [13] [14] where the unsteady characteristics of circular-cylinder flow are captured.

In each measurement of force and pressure, an average value for sampling number 1024 was calculated, which was repeated three times, and further the average for three times is shown with error bars of maximum and minimum averages as the results.

\subsection{Experimental Conditions}

The test model covers 48 combinations from the six heights with the lower or upper position for the air intake, existence and non-existence of the radiator, the two types of engine loading systems. The road clearance for the test model is 30 $\mathrm{mm}$.

The flow conditions were $20 \mathrm{~m} / \mathrm{s}$ for both the wind speed and the moving-belt speed. It has been confirmed that uniform flow is maintained up to the vicinity of the ground board by the moving belt with boundary layer suction at measurement points shown in Figure 6, not only along the belt center but also up to the vicinity of the belt side ends [15]. Typical velocity profiles are shown in Figures 6(a)-(c). The Reynolds number based on the vehicle full length is 1.3 $\times 10^{6}$.

\section{Results}

In the force measurements in Section 3.1, results for both the lower and upper positions for air-inlet opening are shown, whereas in Section 3.2 and later, results for the lower position only are shown, as it is taken in much in domestic passenger cars.

\subsection{Aerodynamic Characteristics}

Figures 7-9 show $C_{D}, C_{L F}$ and $C_{L R}$ on the vertical axis, respectively, for change of opening heights of the air intake on the horizontal axis, where (a) and (b) indicate the cases without and with radiator, respectively. 


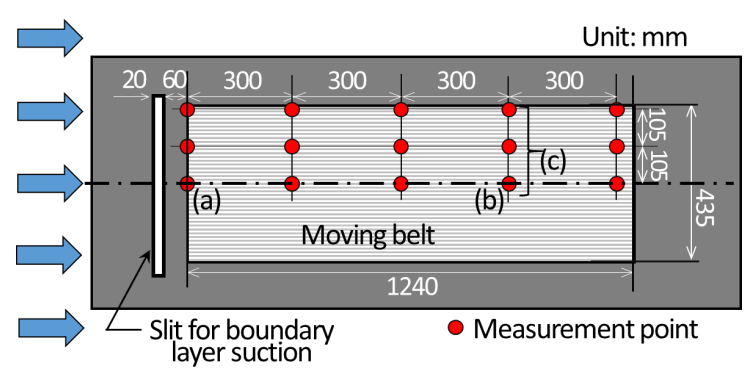

Location of measurement points for velocity profiles

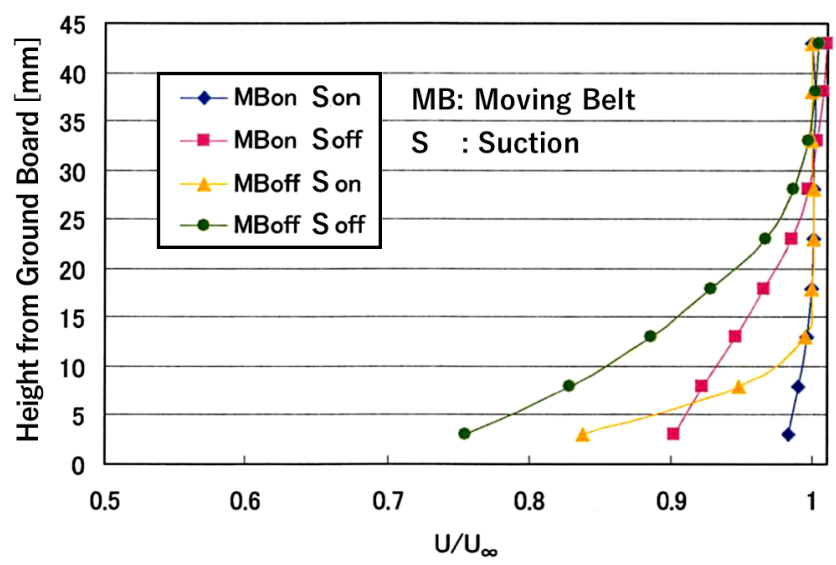

(b) At $900 \mathrm{~mm}$ from front end of belt on center

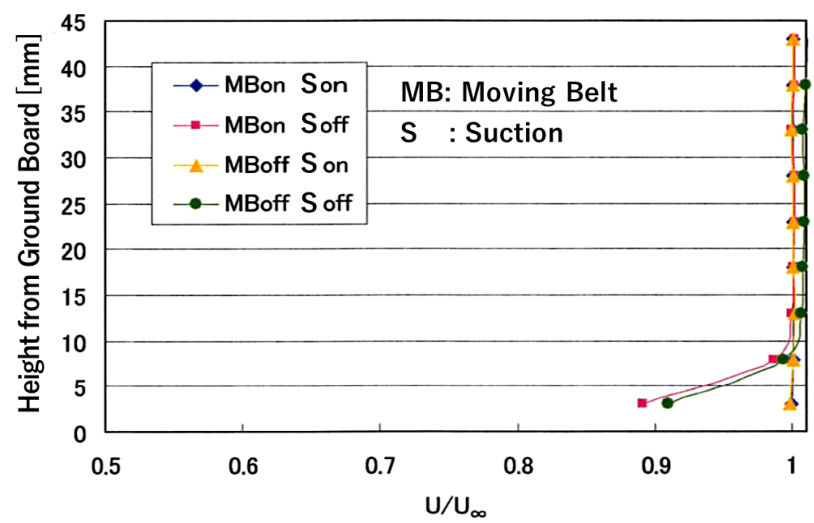

(a) At front end of belt on center

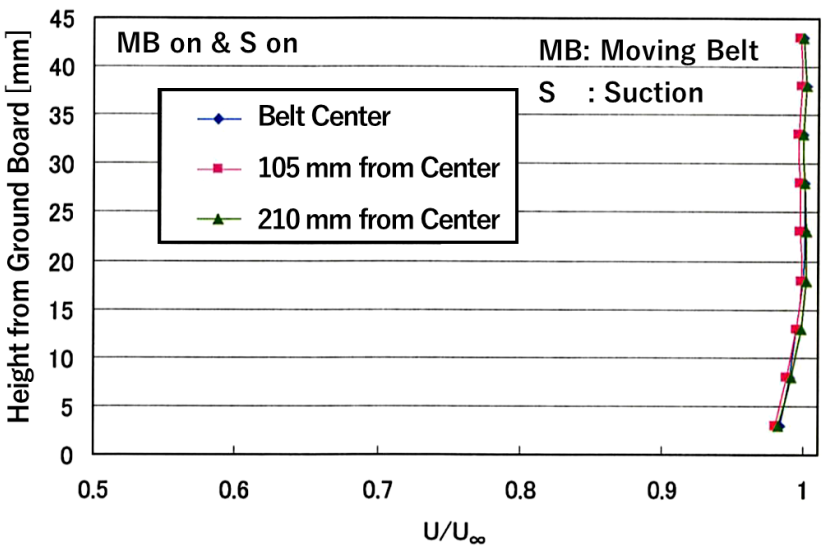

(c) At $900 \mathrm{~mm}$ from front end of belt from center to side end

Figure 6. Wind velocity profiles on moving belt ground board with boundary layer suction device [15].

In Figure 7(a), with enlargement of the inlet height, $C_{D}$ increases overall, and in Figure 7(b) by equipping the vehicle model with the radiator, the increase tendency is relaxed, and the increase is slighter in the engine loading system of length placement. This leads to the consideration that in the width-placement engine, the inlet opening area has a dominant effect for the drag, while in the length-placement engine, existence or non-existence of a radiator is dominant.

In Figure 8(a), with enlargement of the inlet height, $C_{L F}$ increases. Further in Figure 8 (b) by installing the radiator, the difference due to setting conditions of engine loading system and opening position becomes smaller, and the increase tendency is relaxed with rise at $0 \mathrm{~mm}$ and $20 \mathrm{~mm}$ in inlet height and fall at 80 $\mathrm{mm}$ and $100 \mathrm{~mm}$. By full opening, increase of about 0.5 without the radiator and about 0.2 even with the radiator is observed.

In Figure 9(a), with enlargement of the inlet height, $C_{L R}$ decreases, with difference due to the engine loading system and the opening position. In Figure 9(b) with the radiator, the decrease tendency and difference due to the setting conditions is relaxed.

\subsection{Schematic Flow Patterns}

Figure 10 and Figure 11 show comparison of flow patterns obtained from 


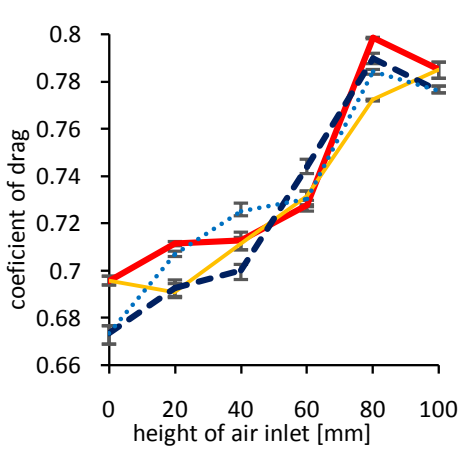

(a) Without radiator

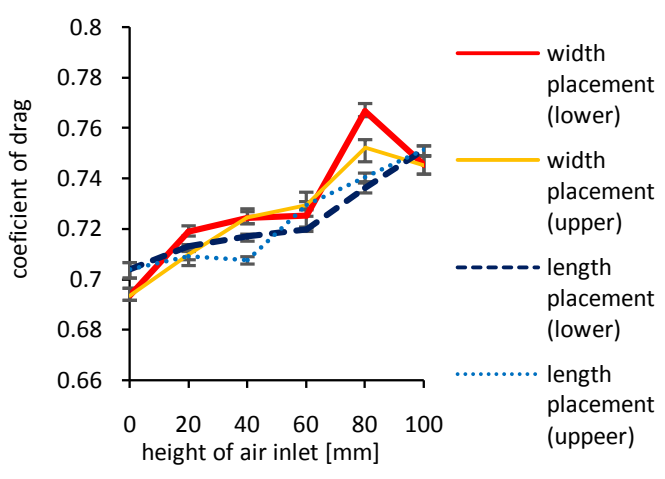

(b) With radiator

Figure 7. Drag coefficients for height of air inlet.

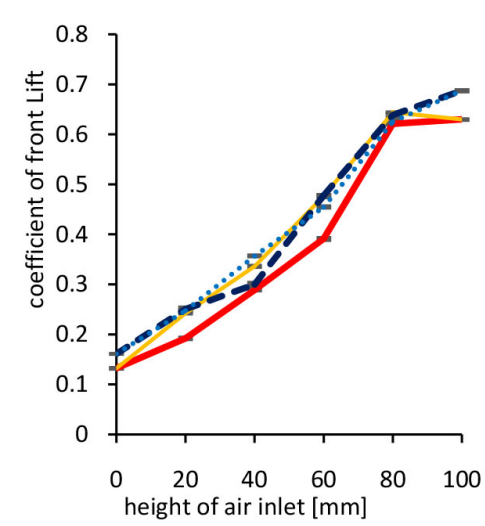

(a) Without radiator.

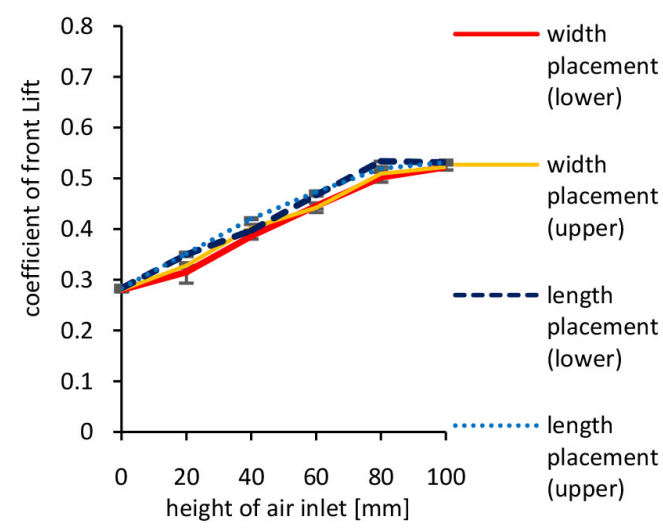

(b) With radiator.

Figure 8. Front lift coefficients for height of air inlet.

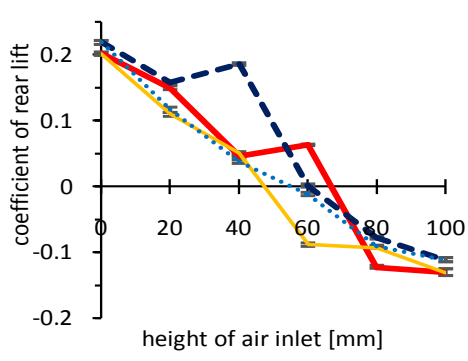

(a) Without radiator

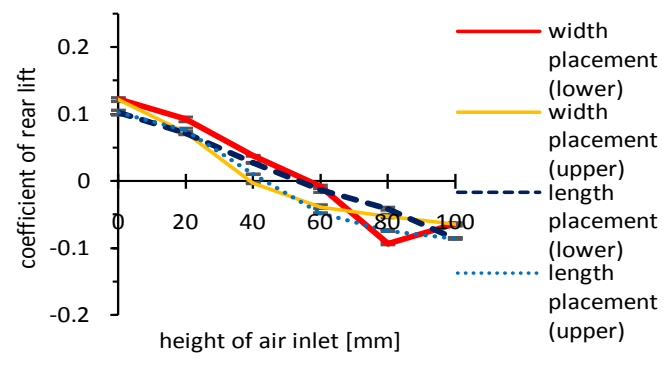

(b) With radiator

Figure 9. Rear lift coefficients for height of air inlet.

visualization of the smoke method about the engine compartment between the width-placement engine and length-placement engine, for lower position of opening height, (a) $20 \mathrm{~mm}$ (side and top views), (b) $80 \mathrm{~mm}$ (side and top views) and (c) $80 \mathrm{~mm}$ (oblique top view). Almost same flow patterns were recognized without and with the radiator, except that with the radiator, in addition to the patterns shown in Figures, there was flow escaping downward from the gap between the front end and overall flow velocity was observed slower. 


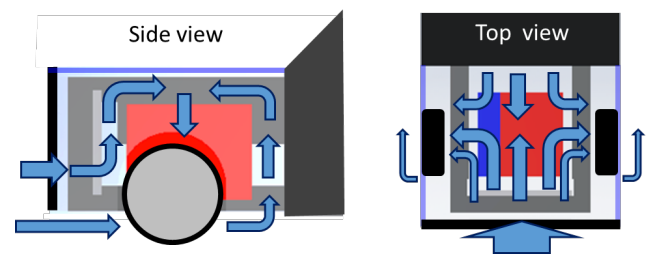

(a) Inlet height $20 \mathrm{~mm}$.

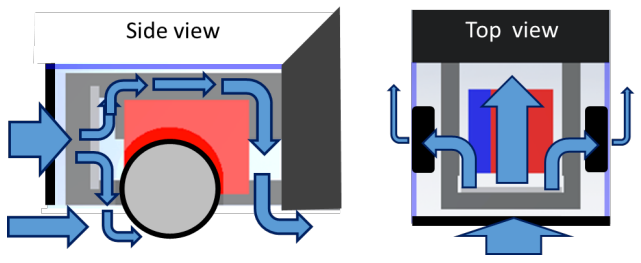

(b) Inlet height $80 \mathrm{~mm}$.

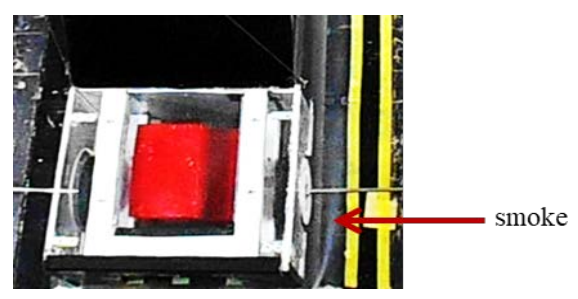

(c) Inlet height $80 \mathrm{~mm}$ (oblique top view).

Figure 10. Schematic flow patterns about engine compartment with width-placement engine.
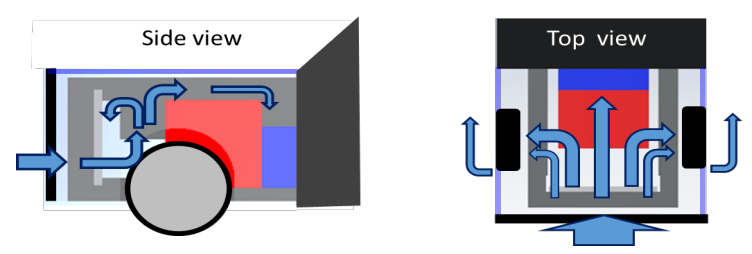

(a) Inlet height $20 \mathrm{~mm}$.
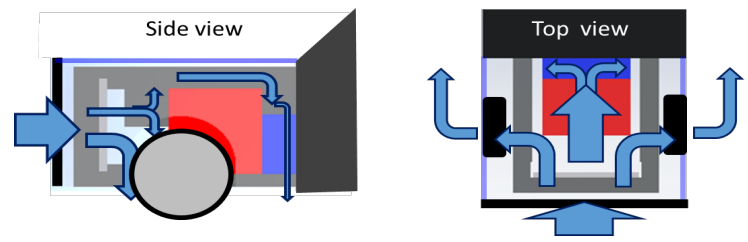

(b) Inlet height $80 \mathrm{~mm}$.

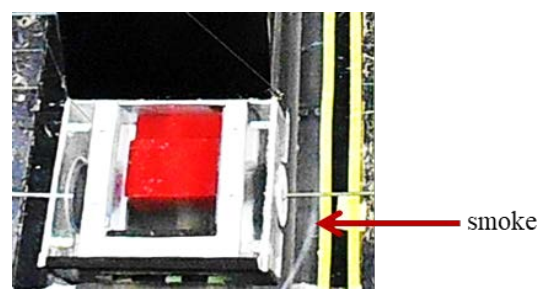

(c) Inlet height $80 \mathrm{~mm}$ (oblique top view).

Figure 11. Schematic flow patterns about engine compartment with length-placement engine. 
In Figure 10 for the width-placement engine, in (a) for opening height 20 $\mathrm{mm}$, fluid entering from the inlet into the engine compartment flows up to the engine top surface, while fluid entering from the underfloor behind the engine unit winds up to the engine top. The two-course flow meets on the engine top surface and slightly exits through the wheel housing. In (b) for opening height $80 \mathrm{~mm}$, fluid entering from the inlet runs up, passes over the engine top, and flows out behind the engine unit to the underfloor, while fluid entering from the lower side of the inlet flows out of the engine front to the underfloor. A slight outflow through the wheel housing is also observed. Compared with (a), winding up behind the engine unit is not identified.

In Figure 11 for the length-placement engine, comparing the cases of opening height (a) $20 \mathrm{~mm}$ and (b) $80 \mathrm{~mm}$, fluid entering from the inlet into the engine compartment flows up and passes over the engine top with disturbance, regardless of the inlet height. Regarding the outflow, in (a) for height $20 \mathrm{~mm}$, outflow only through the wheel housing to the outside of the fender was identified, whereas in (b) for height $80 \mathrm{~mm}$, fluid passing over the engine top flows out through both sides of the transmission to the underfloor and also through the wheel housing to the outside of the fender. Fluid entering from the lower side of the inlet flows out of the engine front directly to the underfloor.

Cases (c) in Figure 10 and Figure 11 show oblique top view for opening height $80 \mathrm{~mm}$ when the smoke is generated at a side corner of the front end. Comparing the smoke top views, it is observed that smoke flows to outer side of the fender more in the length placement engine, which suggests that the outflow rate from the wheel housing is higher in the length placement engine than in the width placement engine.

\subsection{Flow Velocity and RMS under Floor}

Figure 12 shows the measurement position of underfloor flow velocity at the center between the moving belt and the vehicle underfloor (at $15 \mathrm{~mm}$ height from the belt) on the center section of vehicle model, where symbol $\times$ shows unmeasurable range because of interference with rods supporting the vehicle body and wheels. Figure 13 and Figure 14 show (a) underfloor flow velocity with horizontal direction and (b) its RMS in width and length placement engines, respectively.

Figure 13 for the width-placement engine shows the tendency that with increase of the air-inlet height, (a) the underfloor velocity decreases and (b) its RMS increases and that by equipping the vehicle with the radiator RMS distribution is relaxed. That is, in inlet height $20 \mathrm{~mm}$, the local minimum of velocity at $29 \mathrm{~cm}$ distance from the front end and the local maximum of RMS at $24 \mathrm{~cm}$ disappear by installation of the radiator, while in inlet height $80 \mathrm{~mm}$, by the radiator, the velocity distribution does not change clearly but the RMS is lowered after $24 \mathrm{~cm}$ distance.

Figure 14 for the length-placement engine shows that tendency of both velocity and RMS distributions is divided by the presence or absence of the radiator. 


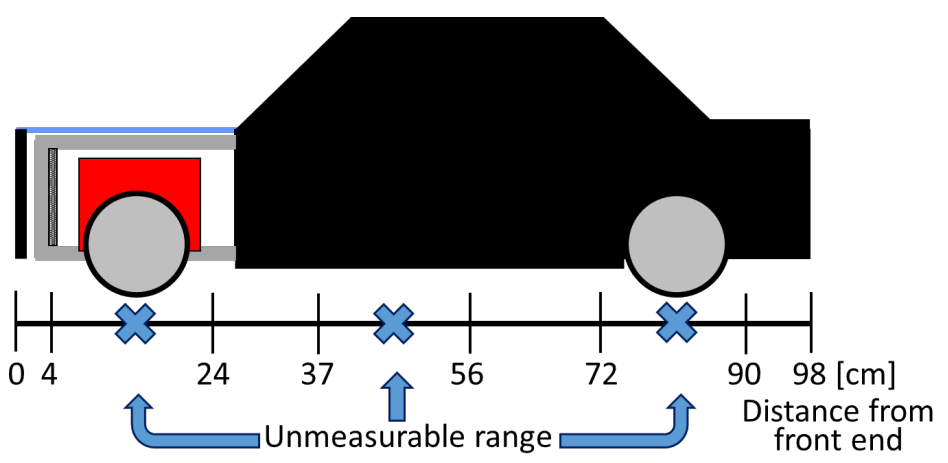

Figure 12. Measurement position of underfloor flow velocity.

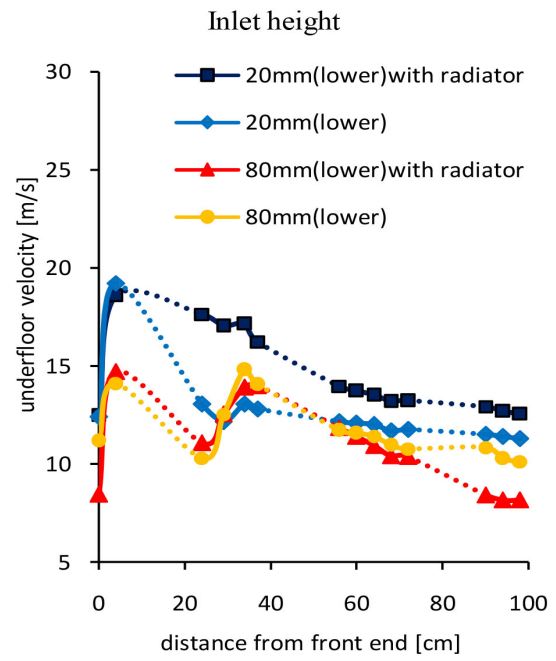

(a) Flow velocity.

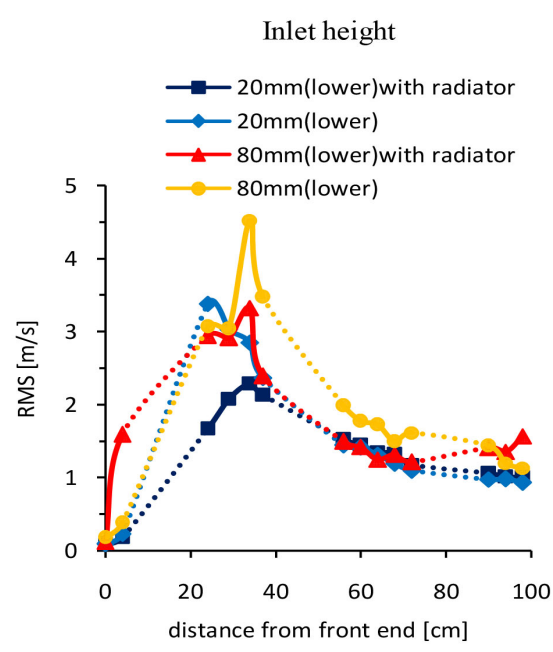

(b) RMS.

Figure 13. Distribution of flow velocity and RMS under floor in width-placement engine.

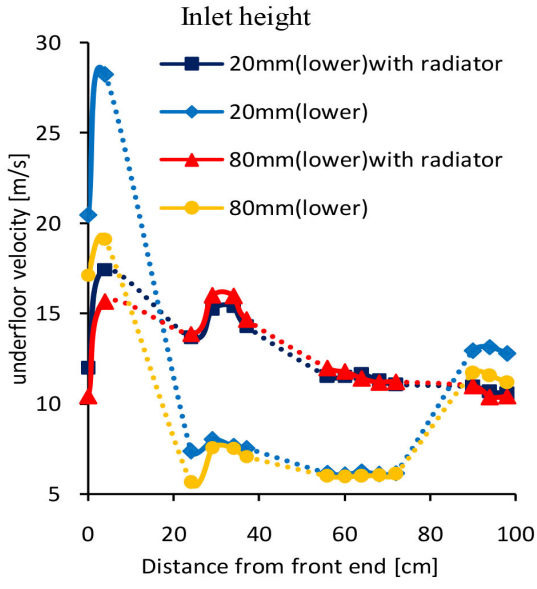

(a) Flow velocity.

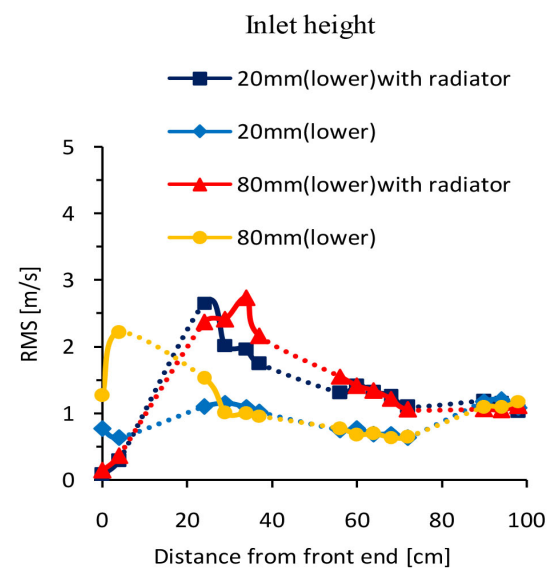

(b) RMS.

Figure 14. Distribution of flow velocity and RMS under floor in length-placement engine.

In the cases without the radiator, as the inlet height increases, (a) the flow velocity is lower and (b) its RMS is higher under the engine compartment. In the cases with the radiator, for increase of the inlet height, the peak velocity at $4 \mathrm{~cm}$ 
slightly decreases, and the maximum RMS does not change but transference of peak position from $24 \mathrm{~cm}$ to $34 \mathrm{~cm}$ distance makes RMS larger in range from 29 $\mathrm{cm}$ to $60 \mathrm{~cm}$ in inlet height $80 \mathrm{~mm}$.

By comparing Figure 13 and Figure 14, it is observed that in the lengthplacement engine the maximum velocity is higher and the peak RMS is mostly lower than those in the width-placement engine.

\subsection{Pressure Distribution on Vehicle Body}

Figure 15 indicates the measurement points of pressure at the center section of model, where pressure holes are arranged at intervals of $20 \mathrm{~mm}$. Figures 14 and 15 show pressure distribution on the underfloor in (a) and on the cabin in (b) in width- and length-placement engines, respectively.

Both Figure 16 and Figure 17 for the width and length placements show the same tendency. With increase of air-inlet height, in (a) pressure distributions under the floor decrease, and in (b) pressure distributions increase on the front window, decrease on the roof, and hardly change on the rear window; by installing the radiator, in (a) underfloor pressure rises toward recovery, while in (b) pressure on the cabin hardly changes. As to the flow on the cabin, usually in attached flow, pressure becomes high at a concave part such as starting point (No. 61) of the cabin and low at a convex part such as starting point (No. 53) of the roof. In this model with a rectangular bonnet focused on the engine cooling flow, since it was confirmed by the smoke method that flow separates at the front corner of the vehicle body and reattaches on the front window, it is considered that the local-maximum pressure cannot be captured at No. 61, but after the reattachment the local-minimum pressure is captured at point No. 53. Because of the separation and reattachment, the error ranges are larger on the front window.

Next, we compare results in more detail between width- and length-placement engines in Figure 16 and Figure 17, respectively. As to the underfloor pressure in (a), in the length placement, effect of the radiator appears slightly in both cases of $20 \mathrm{~mm}$ and $80 \mathrm{~mm}$, while in the width placement, effect of the radiator is enhanced in inlet height $80 \mathrm{~mm}$ : in the vicinity of point No.1, the change of pressure due to the inlet height is larger and without the radiator the pressure values are significantly lower than in the length placement. As to the cabin pressure in (b), the pressure on the front window is higher in the width placement than in the length placement.

In addition, at the rear end of the vehicle body (point Nos.27-31) it was confirmed by measurements that the difference of surface pressure due to change of the inlet height and the radiator is small.

\subsection{Pressure Distribution about Engine Compartment}

About the engine-transmission unit, pressure holes are arranged at intervals of $30 \mathrm{~mm}$ on its center section for the width- and length-placement engines. In the 


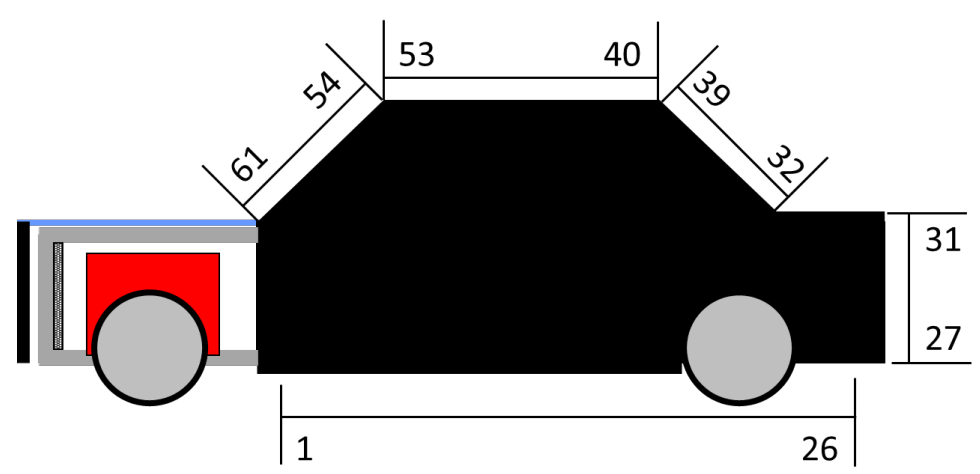

Figure 15. Measurement points of pressure on vehicle-body surface.

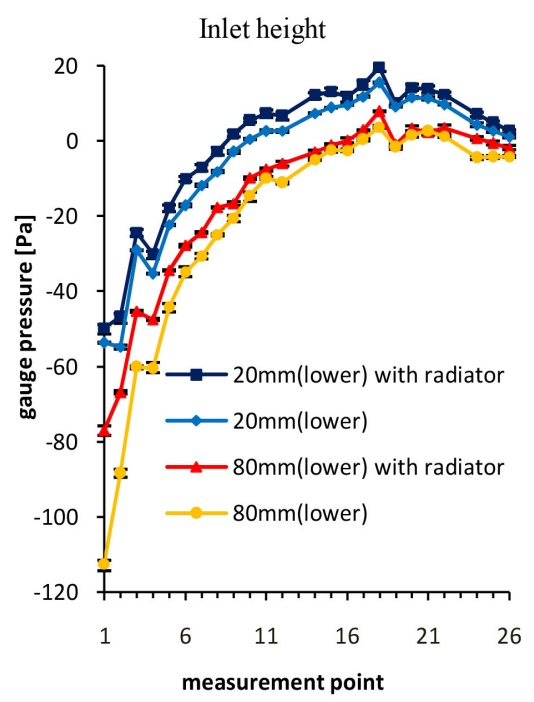

(a) Underfloor.

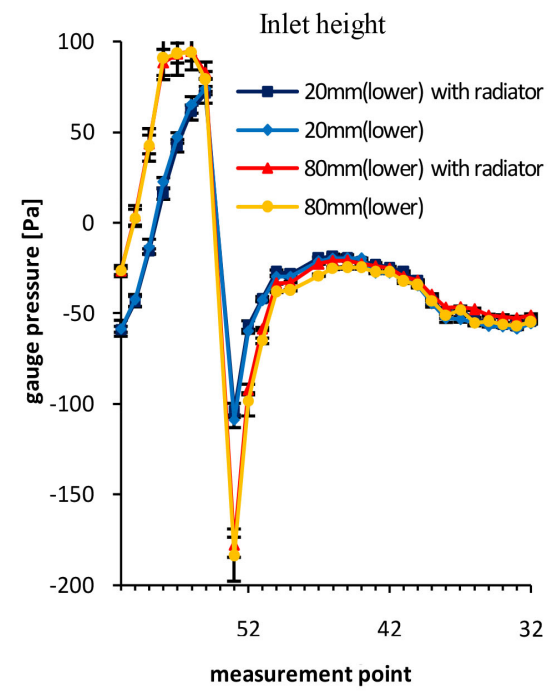

(b) Cabin.

Figure 16. Pressure distribution on vehicle body in width-placement engine.

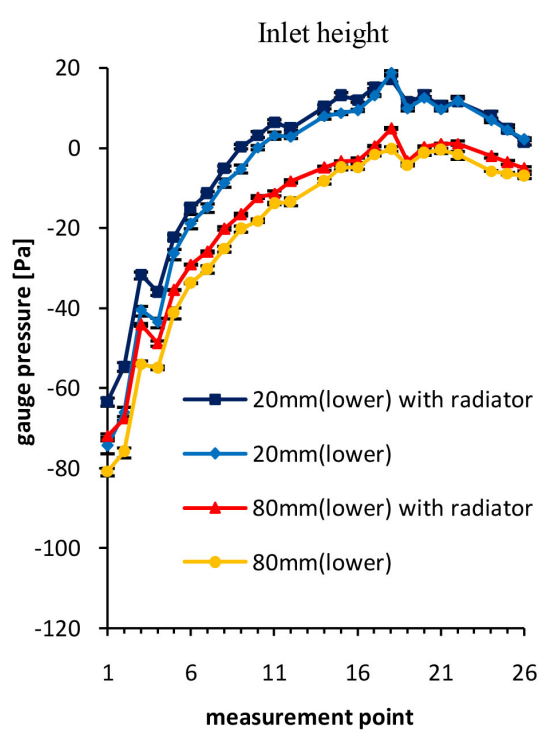

(a) Underfloor.

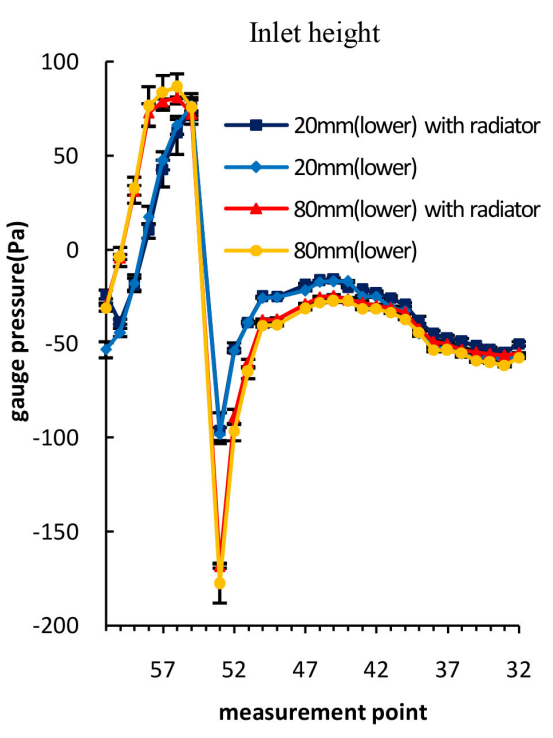

(b) Cabin.

Figure 17. Pressure distribution on vehicle body in length-placement engine. 
width placement, on the right half of the back board behind the engine-transmission unit, pressure holes are arranged in a grid pattern with intervals of 20 $\mathrm{mm}$. Two arrangements of the engine unit are possible with the right grid pattern behind the engine side and the transmission side.

Figure 18 shows pressure about the engine compartment in the width placement: pressure distributions about the engine unit (a) on top surface, (b) on front surface, (c) on bottom surface, (d) on engine back, and (e) pressure distributions on the back board behind the engine unit in the case with the radiator. Figure 19 shows those in the length placement, without (d) and (e) because there is no space between the engine unit and the back board.

In Figure 18 about the width-placement engine, overall tendencies can be summarized as follows. (a) On the engine top, pressure in each case increases toward the rear direction, with increase of the inlet height the pressure increases, and by installing the radiator the pressure decreases. (b) On the engine front, with increase of the inlet height the pressure increases. Effect of the radiator is, in inlet height $80 \mathrm{~mm}$, to decrease the pressure. On the other side, in inlet height $20 \mathrm{~mm}$ without radiator, the pressure at upper points, Nos. 5 and 6 , is low but the pressure at lower point No. 7 is as high as that in inlet height $80 \mathrm{~mm}$, because the pressure hole is located at almost same height of the upper end of the intake opening, and the fluid impinges directly to hole No. 7 on the engine front, while by installing the radiator the front pressure distribution is relaxed to be uniform. (c) On the engine bottom, pressure in each case increases toward the rear direction, with increase of the inlet height the pressure increases, and by installing the radiator the pressure distribution in space is relaxed to have an almost constant pressure gradient. (d) On the engine back, by increasing the inlet height the pressure becomes high with uniform distribution in space and by installing the radiator the pressure decreases remarkably in inlet height $80 \mathrm{~mm}$ and slightly in inlet height $20 \mathrm{~mm}$. (e) On the back board behind the engine-transmission unit, in the case with the radiator, by increasing the inlet height the pressure increases, resulting in slightly higher values in inlet height $80 \mathrm{~mm}$ and lower values in inlet height $20 \mathrm{~mm}$ than those on the engine back shown in (d).

In Figure 19 about the length-placement engine, overall tendencies are as follows. (a) On the engine top, by increasing the inlet height the pressure becomes high with almost uniform distribution in space, and by installing the radiator the pressure decreases greatly in inlet height $80 \mathrm{~mm}$ and slightly in inlet height 20 $\mathrm{mm}$. (b) On the engine front, with increase of the inlet height the pressure increases. By installing the radiator, in inlet height $80 \mathrm{~mm}$ the pressure decreases remarkably, while in inlet height $20 \mathrm{~mm}$ the pressure is made uniform with slight increase, showing the same tendency as in Figure 18(b). (c) On the engine bottom, pressure in each case increases toward the rear direction. Without the radiator, by increasing the inlet height the pressure becomes high, while by installing the radiator the pressure decreases, and above all in inlet height $80 \mathrm{~mm}$ it does drastically with pressure values lower than those in inlet height $20 \mathrm{~mm}$. 


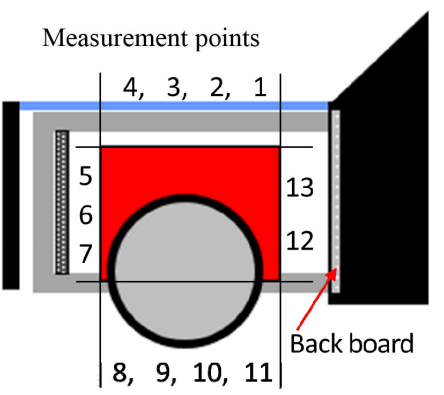

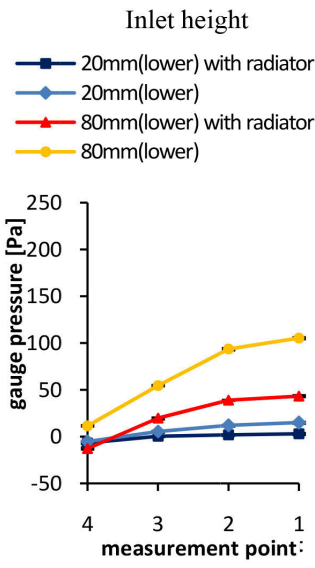

(a) On engine top.

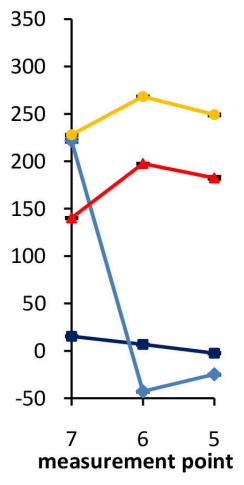

(b) On engine front.

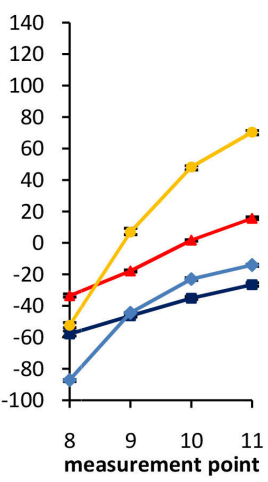

(c) On engine bottom.

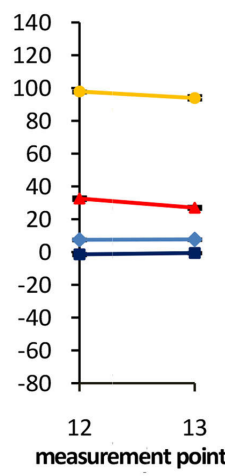

(d) On engine back.

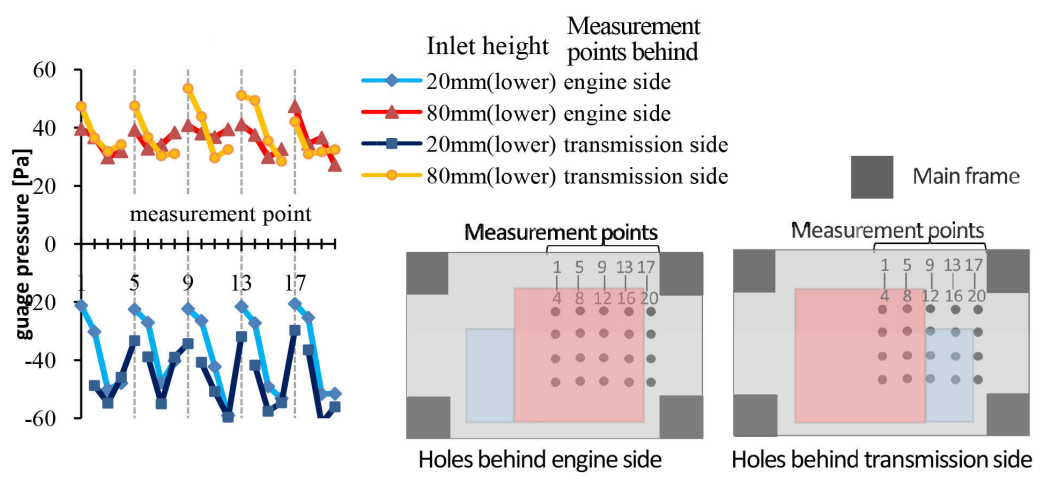

(e) On back board in case with radiator.

Figure 18. Pressure distribution about engine compartment with width-placement engine.

Comparing the pressure values in (a) to (c) between Figure 18 and Figure 19, the difference appears prominently in inlet height $80 \mathrm{~mm}$ : in the length placement the pressure is higher with larger error ranges in absence of the radiator and is lower in presence of the radiator than in the width placement

\section{Discussion}

We discuss effects on enlargement of the air-inlet height by comparison between inlet heights $20 \mathrm{~mm}$ and $80 \mathrm{~mm}$.

\subsection{Engine Loading System: Width Placement}

In the width placement as engine loading system, same tendencies for the 


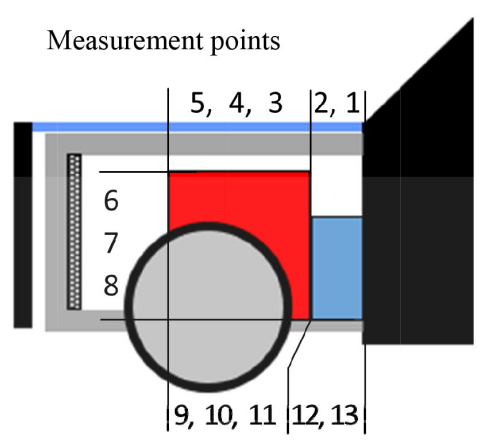

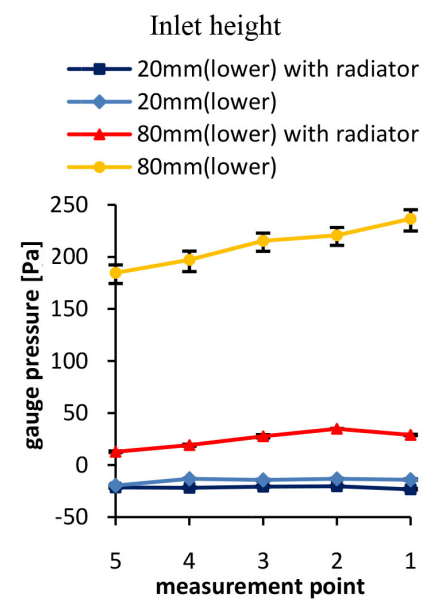

(a) On engine top.

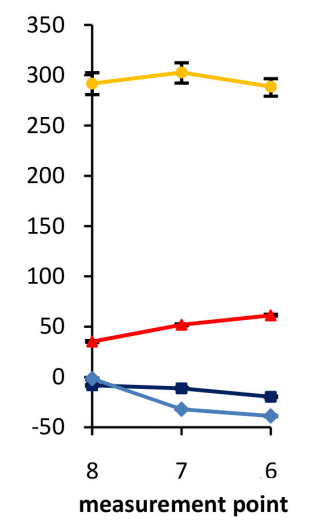

(b) On engine front.

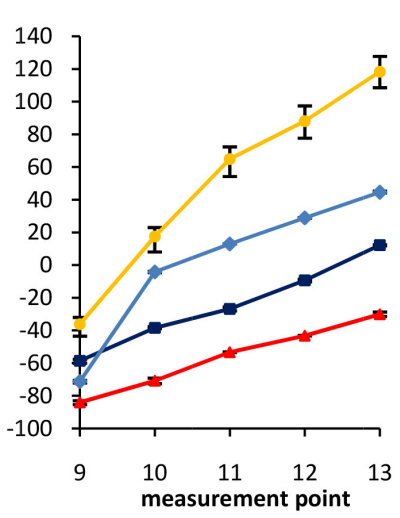

(c) On engine bottom.

Figure 19. Pressure distribution about engine compartment with length-placement engine.

change of the air-inlet height have been shown in each case with and without the radiator. First, we consider causes for increase of $C_{D}$ due to enlargement of the inlet height shown in Figure 7. As the inlet height is enlarged, the pressure within the engine compartment increases (Figure 18), and the drag increase is due to increase of the pressure difference between the front and back of the engine unit and also due to increase of the pressure on the back board behind the engine unit. Further, the pressure on the engine bottom increases and so does the pressure at the frontward side, which is considered to be connected with the pressure on the front end of the vehicle body, and accordingly the pressure on the front window also increases (Figure 16(b)); thus the drag increase is also considered to be due to high pressure on the front end and front window of the vehicle body induced by high pressure inside the engine compartment. The pressure on the rear window and on the rear end does not largely affect the drag, because the pressure change was very small.

Regarding flow about the engine compartment, with enlargement of the inlet height, the outflow from the engine compartment toward the underfloor increases (Figure 10), which causes disturbance of flow (Figure 13(b)) due to merging with the underfloor flow coming from the vehicle front, making it difficult to pass the underfloor flow. Thus the underfloor velocity decreases (Figure 13(a)), and the pressure on the engine bottom increases (Figure 18(c)). On the 
other hand, high pressure near the engine allows airflow to escape outward from the wheel housing (Figure 10).

Summarizing the above, increase of the inlet height causes pressure rise inside the engine compartment, which in turn increases the pressure on the front end and front window of the vehicle body, and, at the same time, increases the outflow rate of scavenging from the engine compartment to the underfloor. Consequently, by confluence with the underfloor flow, the flow is disturbed to have the effect of blocking the underfloor flow, and so the flow velocity decreases and pressure increases under the engine compartment, which keeps the high pressure inside the engine compartment and matches the pressure on the upper front part of the vehicle body. Thus $C_{D}$ increases with enlargement of the inlet height.

Next, we consider causes for increase of $C_{L F}$ with enlargement of the inlet height shown in Figure 8. It is due to the pressure rise under the engine unit (Figure 18(c)), the reason of which has been discussed in the cause of the increase in drag. Also, as shown in Figure 16(b), the pressure drop in the front of roof leads to the increase of the front lift, although the pressure rise on the front window causes its decrease. Further, due to increase of the downward flow scavenging from the engine compartment (Figure 10(b)), the wall of flow pathway in the engine compartment receives an upward force (lift force) as a reaction for the downward momentum that the fluid obtains.

Finally, decrease of $C_{L R}$ with enlargement of the inlet height (Figure 9) is considered to be due to the pressure decrease under the floor of the vehicle body behind the engine compartment (Figure 16(a)). As discussed in the cause of the increase in drag, the scavenging flow causes the flow disturbance, resulting in energy loss behind the engine compartment, which leads to the pressure fall. The pressure on the rearward of roof and on the rear window does not largely contribute to the rear lift because the pressure change due to enlargement of the inlet height is very small.

Furthermore, the reason why the radiator reduces the range of changes in drag and lift in Figures 7-9 is discussed below. In each of inlet height $20 \mathrm{~mm}$ and $80 \mathrm{~mm}$, the pressure distributions in Figure 16 and Figure 18 change so that the opening height decreases due to the attachment of the radiator. This suggests that the passage inflow rate is reduced by installing the radiator, and in fact, a slight flow escaping downward from the front of the radiator and slower flow velocity after the radiator was observed by the smoke method (see Section 3.2). The drag change in Figure 7 shows the effect of reducing the opening height by the radiator. However, the changes of front and rear lift in Figure 8 and Figure 9 show the same reduction effect for the larger inlet height, but show the opposite effect for the smaller inlet height. The reason of the latter is considered that by installation of the radiator, the downward momentum of the scavenging air from the engine compartment increases, so that the front lift increases, and the rear lift decreases due to the moment balance around the support point. 


\subsection{Engine Loading System: Length Placement}

In the length placement as engine loading system, first, we consider causes for increase of $C_{D}$ due to enlargement of the air-inlet height shown in Figure 7. Without the radiator the drag increases as in the width placement engine, but with the radiator the increase is slighter. Also from distributions of the underfloor velocity and RMS (Figure 14) and the engine-unit surface pressure (Figure 19), it is considered that the presence or absence of the radiator has a great influence on the drag, above all, at inlet height $80 \mathrm{~mm}$ in the length placement.

As the inlet height is enlarged, the pressure on the front and top surfaces of the engine unit increases uniformly in space (Figure 19). Without the radiator, at inlet height $80 \mathrm{~mm}$, pressure is significantly high; above all, the pressure on the engine top is higher by $100 \mathrm{~Pa}$ than the highest value in the corresponding case for the width placement engine. The reason is considered that the high stagnation pressure on the rectangular engine front is maintained near the engine unit because the upper space of the transmission is almost blocked by the engine, the bonnet and the back board. Even with the radiator, the pressure also increases due to the inlet height although the rise is very small. Thus, a cause of the drag increase is the pressure rise on the engine front and on the back board.

About the pressure around the vehicle body, first the pressure under the engine unit (Figure 19(c)) is examined. As the inlet height is enlarged, without the radiator the pressure on the engine bottom increases, whereas with the radiator it decreases and in inlet height $80 \mathrm{~mm}$ the pressure shows the lowest with the pressure gradient smaller. It is considered that on the front end of the vehicle body the pressure does not vary much due to existence or non-existence of the radiator. The pressure on the front end would affect the pressure on the front window, which accordingly increases without and with the radiator (Figure 17(b)); thus another cause of the drag increase is high pressure on the front end and window of the vehicle body induced by high pressure in the vicinity of the engine unit. The pressure on the rear window and on the rear end does not largely affect the drag, because the pressure difference is small.

Regarding flow about the engine compartment, with enlargement of the inlet height, the outflow from the engine compartment toward the underfloor increases through the front of the engine and both sides of the transmission (Figure 11). In absence of the radiator the underfloor velocity decreases with increase of its RMS (Figure 14), and the pressure under the engine compartment increases (Figure 19(c)). This is considered to come from the effect of blocking the underfloor flow by underfloor disturbance due to the engine scavenging flow, as discussed in Section 4.1. On the other side, with the radiator, the reason for the decrease of pressure on the engine bottom (Figure 19(c)) is expected that under the floor the RMS decreases and the underfloor velocity increases. In Figure 14, however, such tendency for RMS and velocity does not clearly appear. This might be because the velocity measurement was carried out for horizontal direction only. In addition, due to the positional relationship be- 
tween the wheels and the engine, the high pressure in the vicinity of the engine unit allows airflow to easily escape outward from the wheel housing (Figure 11).

Summarizing the above, increase of the inlet height causes significantly high pressure on the engine unit due to the forward block by the length-placement engine, and the scavenging flow merges with the underfloor flow to make disturbance, which has blockage effects for both the scavenging flow and the underfloor flow. The former effect keeps the high pressure in the vicinity of the engine unit and the latter effect makes the pressure high under the engine unit without the radiator. Although the radiator considerably affects the pressure about the engine unit, the pressure at the front end of the vehicle body is not considered to differ greatly depending on the presence or absence of the radiator. The high pressure in the vicinity of the engine unit matches the pressure on the front part of the vehicle body. Thus $C_{D}$ increases with enlargement of the inlet height.

Next, we consider causes for increase of $C_{L F}$ with enlargement of the inlet height shown in Figure 8. Without the radiator, the pressure rise under the engine (Figure 19(c)), which is due to the blocking effect of the underfloor flow by disturbance, contributes to increase of the front lift. With the radiator, the pressure fall under the engine has the decreasing effect of front lift, which leads to relaxing effect. Further, the pressure drop in the front of roof (Figure 17(b)) and the increase in the downward scavenging flow (Figure 11) also lead to the increase of the front lift as discussed in Section 4.1, not depending on existence or non-existence of the radiator.

Finally, causes for decrease of $C_{L R}$ with enlargement of the inlet height shown in Figure 9 is considered to be same as in the width-placement engine.

Furthermore, the reason why the radiator reduces the range of changes in drag and lift in Figures 7-9 is almost same as discussed in the width-placement engine. The difference is that by installing the radiator, at inlet height $20 \mathrm{~mm}$ the pressure on the engine front slightly increases instead of changing toward decrease of the inlet height. Thus, the radiator relaxes the drag increase with drop for the larger inlet height and rise for the smaller inlet height in Figure 7.

\subsection{Comparison between Width and Length Placements of Engine}

Overall correlation of phenomena caused by the cooling flow is almost same in both the width and length placement engines in that enlargement of the inlet height (and therefore increase of the inflow rate) causes pressure rise inside the engine compartment, and further adapts to that on the upper front surfaces of the vehicle, but causes pressure fall under the floor behind the engine compartment. These phenomena are due to flow disturbance by merging of the scavenging flow and the underfloor flow, which has blockage effects for the upstream of each flow with keeping high pressure in the vicinity of the engine unit (except for the pressure on the bottom of the length-placement engine with the radiator) and causes pressure loss in the downstream of the merging disturbance under the floor. 
The differences of phenomena between the two engine loading systems arise from placement direction (width or length direction) and location (distance from the air inlet to the engine front) of the engine-transmission unit inside the engine compartment. Here, focusing on inlet height $80 \mathrm{~mm}$ where remarkable difference appeared, we discuss the comparison.

In the length placement without the radiator, fast flow runs against the square shape of the engine front with higher stagnation pressure generated than against the notched square shape of the engine-unit front in the width placement ((b) in Figure 19 and Figure 18), and due to the shape almost surrounded by the engine unit and the backboard, the pressure becomes much higher in top of the engine unit ((a) in Figure 19 and Figure 18). However, the pressure on the front end of the vehicle body is considered to be lower, since the distance from the air inlet to the engine is longer and through the wider space the fluid easily flows out more from the upstream side of the engine to the underfloor and to the outside of the fender with induction by the rotation of wheels ((b) in Figure 11 and Figure 10). The lower pressure at the front end would induce the lower pressure distribution on the front window ((b) in Figure 17 and Figure 16). Thus, the pressure is higher in the vicinity of the engine unit but lower on the front end and the front window, which leads to the drag slightly smaller in Figure 7(a) without the radiator, at inlet height $80 \mathrm{~mm}$ with lower position, compared with the width placement.

By installing the radiator in the length placement, the pressure on the engine front is considerably lower than in the width placement ((b) in Figure 19 and Figure 18). The reason is considered that, in the length placement the slow stream behind the radiator flows out more from the upstream side of the engine to the underfloor and to the outside of the fender as stated in the previous paragraph, so the velocity of flow in the straight direction would be further lowered, and the stagnation pressure on the engine front becomes lower. The pressure on the front end of the vehicle body would not change much due to the radiator as stated in Section 4.2, and so the pressure on the front window would not. Thus, the lower pressure in the vicinity of the engine unit and on the front end and window leads to the drag quite lower in Figure 7(b) with the radiator, at inlet height $80 \mathrm{~mm}$ with lower position, compared with the width placement.

As the factor of the drag increase due to enlargement of the inlet height, in the length placement, the change of pressure in the vicinity of the engine unit is stronger without the radiator and the change of pressure on the front end and window of the vehicle is weaker than in the width placement.

In the width placement, since there are spaces in front of the engine unit and behind that, the scavenging flow can run out of the spaces to the underfloor, while in the length placement, since there is no space between the transmission and the backboard, the scavenging flow runs out of the front side of the engine and both the sides of the engine unit to the underfloor, and runs away out of the wheel housing to outside of the fender ((b) in Figure 10 and Figure 11). Therefore, in the width placement, the outflow rate of scavenging to the underfloor 
would be higher and the disturbance is generated more overall under the floor ((b) in Figure 13 and Figure 14), with energy loss higher, resulting in lower underfloor pressure in the downstream of the engine compartment. In comparison of (a) between Figure 16 and Figure 17, in the vicinity of hole No.1 the pressure is remarkably lowered on the underfloor center line, although the point would contribute to the front lift. Not only on the center line but also on the whole underfloor surface the pressure loss is considered to spread more in the width placement. The lower underfloor pressure leads to the lowest rear lift at inlet height $80 \mathrm{~mm}$ with lower position in Figure 9(a) and Figure 9(b), without and with the radiator.

\subsection{Reduction of Aerodynamically Undesirable Influences}

From the previous Sections 4.1 to 4.3 , the principle to simultaneously decrease drag and lift is considered to avoid interference of the engine-compartment scavenging flow with the underfloor flow coming from the upstream side to reduce disturbance under the floor, which suppresses pressure rise inside the engine compartment, and accordingly on the front end and front window of the vehicle body. In underfloor scavenging, scavenging toward the rear of the vehicle body is considered effective to avoid interference between the engine cooling airflow and the underfloor. One example is attachment of an engine undercover [8]. Other than underfloor scavenging, it would be also effective to perform upward scavenging from the bonnet or sideward scavenging from the fender.

In the length placement without the radiator, since the pressure in the vicinity of the engine unit is remarkably high, above all, upward scavenging from the bonnet is considered effective by making the ventilation port in the bonnet, because the pressure inside the engine compartment is lowered without underfloor disturbance. One example has been demonstrated by the authors [16].

\section{Conclusions}

In this experimental study, the test model was designed to simulate the engine cooling flow that can be applied to almost all domestic vehicle types with a front engine by simplifying common items, and for change of intake opening area the changes of aerodynamic characteristics were investigated with variation of the intake position and the two engine layout of width and length placements in presence or absence of the radiator. The overall results show that with enlargement of the opening area, the drag and the front lift increased and the rear lift decreased. In this model, flow separates at the front corner of the simplified vehicle body but reattaches on the front window. Therefore, it is considered that the tendency of change in drag and lift is universally applicable to real road vehicles without separation at the rounded front end, but with lower drag.

Here it has been clarified that the cause of the change in aerodynamic characteristics due to the cooling airflow is disturbance under the floor due to merging of the engine scavenging flow and the underfloor flow. In the correlation of 
phenomena, enlargement of the air-inlet height (and therefore increase of the cooling flow rate) causes pressure rise inside the engine compartment, and further adapts to that on the front end and window of the vehicle, but causes pressure fall under the floor behind the engine compartment. It is due to the flow disturbance above stated, which has blockage effects for each upstream of scavenging flow and underfloor flow with keeping high pressure in the vicinity of the engine unit (except for the pressure on the bottom of the length-placement engine with the radiator) and causes pressure loss in the downstream of the merging disturbance under the floor.

Further, it has been shown that differences in flow features and aerodynamic characteristics between the two engine loading systems arise from direction and position of the engine unit inside the engine compartment.

Aerodynamic effects by engine cooling flow can be summarized: 1) The drag depends on the pressure inside the engine compartment and on the front end and the front window of the vehicle body; 2) The front lift depends on the pressure under the engine unit, and on the front window and the fore part of the roof; it also depends on momentum of flow scavenging from the engine compartment to the underfloor; 3) The rear lift depends on the underfloor pressure behind the engine compartment; 4) The installation of the radiator reduces the range of changes in aerodynamic characteristics mainly by reducing effect of the intake area, which appears large on drag in the length-placement engine.

Since the pressure inside the engine compartment is connected with that on the vehicle surface by the pass way of engine cooling flow, the principle to improve drag and lift is considered to avoid interference between the scavenging flow and the underfloor flow. Other than underfloor scavenging without interference, upward scavenging from the bonnet and sideward scavenging from the fender is considered effective. In the length placement engine without the radiator, since the pressure on the engine unit is remarkably high, upward scavenging is recommended.

\section{Acknowledgements}

The authors would like to express their sincere gratitude to Prof. Yoshinobu Inada and lecturer Nobuyuki Arai, Tokai University, for their efforts to maintain the wind tunnel environments.

\section{Conflicts of Interest}

The authors declare no conflicts of interest regarding the publication of this paper.

\section{References}

[1] Wolf-Heinrich, H. (1998) Aerodynamics of Road Vehicles. Fourth Edition, Society of Automotive Engineers, Inc., Warrendale.

[2] Sumitani, K., Maeda, K. and Ichinose, K. (2004) Development of Vehicle Fluid Dy- 
namics: Flow around the Vehicle and Aerodynamic Characteristics. Journal of Japan Society of Fluid Mechanics, 23, 445-454.

[3] Aizawa, S., Matsumoto, R. and Takakura, Y. (2013) Aerodynamic Characteristics and Wake Structures on Car Models Changed by Configuration Parameters. The 12 th International Symposium on Fluid Control, Measurement and Visualization, Nara, Paper No. 0237.

[4] Wiedemann, J. (1986) Theoretical and Experimental Optimization of the Road Vehicle Internal Flow, von Karman IFD.

[5] Barnard, R.H., Bullen, P.R. and Qjao, J. (2004) Fixed and Variable Cooling Outlet Geometries for the Minimisation of Associated Drag. 5 th MIRA International Vehicle Aerodynamics Conference, Warwick.

[6] Baeder, D., Indinger, T., Adams, N.A. and Unterlechner, P. (2013) Interference Effects of Cooling Airflows on a Generic Car Body. Journal of Wind Engineering and Industrial Aerodynamics, 119, 146-157. https://doi.org/10.1016/j.jweia.2013.05.009

[7] Nouzawa, T., Hiasa, K. and Yoshimoto, M. (1989) Influence of Engine Cooling Air Flow on Aerodynamic Drag. Transactions of Society of Automotive Engineers of Japan, No. 40, 76-84.

[8] Ohshima, T., Hamatani, K., Ninoyu, M. and Nakagawa, K. (1998) Influence of the Cooling Air Flow Outlet on Aerodynamic Characteristics. Transactions of Society of Automotive Engineers of Japan, 29, 81-86.

[9] Simmonds, N., Tsoutsanis, P., Drikakis, D., Gaylard, A. and Jansen, W. (2016) Full Vehicle Aero-Thermal Cooling Drag Sensitivity Analysis for Various Pressure Drops. SAE2016 World Congress and Exhibition, SAE 2016-01-1578. https://doi.org/10.4271/2016-01-1578

[10] Zhang, C., Uddin, M., Song, X., Fu, C. and Foster, L. (2016) Simultaneous Improvement of Vehicle Under-Hood Airflow and Cooling Drag Using 3D CDF Simulation. SAE2016 World Congress and Exhibition, SAE 2016-01-0200. https://doi.org/10.4271/2016-01-0200

[11] Sawaguchi, T. and Takakura, Y. (2017) Aerodynamic Effects by Cooling Flows within Engine Room of a Car Model. IOP Conference Series. Materials Science and Engineering, 249, Article ID: 012012. https://doi.org/10.1088/1757-899X/249/1/012012

[12] Kameoka, K. and Takagi, M. (1994) Large-Scale Low-Speed Wind-Tunnel in Japan. Journal of the Visualization Society of Japan, 14, 102-103.

[13] Watanabe, N., Furuta, T. and Takakura, Y. (2014) Characteristics of Unsteady Flows around a Circular Cylinder with Simultaneous Multipoint Measurements of Pressure. Proceedings of the School of Engineering of Tokai University, Series E, 39, 81-88.

https://www.u-tokai.ac.jp/academics/undergraduate/engineering/kiyou/pdf/vol_53_ 002e/14.pdf

[14] Watanabe, N., Furuta, T. and Takakura, Y. (2013) Unsteady Flow around a Circular Cylinder with Simultaneous Multipoint Measurements of Pressure. Proceedings of FLUCOME 2013, OS14-03-3.

[15] Sugimura, D. and Takagi, M. (2006) Study on Improvements of Moving Belt. Graduation Thesis of School of Engineering, Tokai University, Tokyo.

[16] Tashiro, K., Sawaguchi, T. and Takakura, Y. (2019) Reduction of Aerodynamically Undesirable Influences Due to Engine Cooling Airflow of FR Car. Proceedings of the School of Engineering of Tokai University, Vol. 59, 23-30. 


\section{Nomenclature}

$A$ Projected frontal area of vehicle

$C_{D} \quad$ Coefficient of drag $=(\operatorname{drag}) /\left\{(1 / 2) \rho U_{\infty}^{2} \times A\right\}$

$C_{L} \quad$ Coefficient of lift $=C_{L F}+C_{L R}$

$C_{L F}$ Coefficient of front lift $=($ front lift $) /\left\{(1 / 2) \rho U_{\infty}^{2} \times A\right\}$

$C_{L R}$ Coefficient of rear lift $=($ rear lift $) /\left\{(1 / 2) \rho U_{\infty}^{2} \times A\right\}$

$C_{p} \quad$ Pressure coefficient $=\left(p-p_{\infty}\right) /\left\{(1 / 2) \rho U_{\infty}^{2}\right\}$

$P$ Pressure

$p_{\infty}$ Pressure of uniform flow

$U_{\infty}$ Wind speed of uniform flow

$\rho$ Density 